Article

\title{
Experimental Investigation on the Sputtering Process for Tantalum Oxynitride Thin Films
}

\author{
Chuan Li ${ }^{1,2, *(D)}$, Jang-Hsing $\mathrm{Hsieh}^{3}$ and Y. R. Chuang ${ }^{1}$ \\ 1 Department of Biomedical Engineering, National Yang Ming Chiao Tung University, Taipei 11221, Taiwan; \\ erayc1996@ym.edu.tw \\ 2 Department of Mechanical Engineering, National Central University, Jhongli, Taoyuan 32001, Taiwan \\ 3 Department of Materials Engineering, Ming Chi University of Technology, Taishan, Taipei 24301, Taiwan; \\ jhhsieh@mail.mcut.edu.tw \\ * Correspondence: cli10@nycu.edu.tw; Tel.: +886-2-2826-7397
}

check for updates

Citation: Li, C.; Hsieh, J.-H.; Chuang, Y.R. Experimental Investigation on the Sputtering Process for Tantalum Oxynitride Thin Films. Photonics 2021, 8, 53. https://doi.org/10.3390/ photonics 8020053

Received: 2 January 2021

Accepted: 11 February 2021

Published: 15 February 2021

Publisher's Note: MDPI stays neutral with regard to jurisdictional claims in published maps and institutional affiliations.

Copyright: (c) 2021 by the authors. Licensee MDPI, Basel, Switzerland. This article is an open access article distributed under the terms and conditions of the Creative Commons Attribution (CC BY) license (https:// creativecommons.org/licenses/by/ $4.0 /)$.

\begin{abstract}
Metal oxynitrides are compounds between nitrides and oxides with a certain level of photocatalytic functions. The purpose of this study is to investigate an appropriate range of oxygen flow rate during sputtering for depositing tantalum oxynitride films. The sputtering process was carried out under fixed nitrogen but variable oxygen flow rates. Post rapid thermal annealing was conducted at $800^{\circ} \mathrm{C}$ for 5 min to transform the as-deposited amorphous films into crystalline phases. The material characterizations of annealed films include X-ray diffraction and Raman spectroscopy for identifying crystal structures; scanning electron microscope for examining surface morphology; energy-dispersive $\mathrm{X}$-ray spectroscopy to determine surface elemental compositions; four-point probe and Hall effect analysis to evaluate electrical resistivity; UV-visible-NIR spectroscopy for quantifying optical properties and optical bandgaps. To assess the photocatalytic function of oxynitride films, the degradation of methyl orange in de-ionized water was examined under continuous irradiation by a simulated solar light source for six hours. Results indicate that crystalline tantalum oxynitride films can be obtained if the $\mathrm{O}_{2}$ flow rate is chosen to be $0.25-1.5 \mathrm{sccm}$ along with $10 \mathrm{sccm}$ of $\mathrm{N}_{2}$ and $20 \mathrm{sccm}$ of Ar. In particular, films deposited between 0.25 and $1.5 \mathrm{sccm} \mathrm{O}_{2}$ flow have higher efficiency in photodegradation on methyl orange due to a more comprehensive formation of oxynitrides.
\end{abstract}

Keywords: tantalum oxynitride; rapid thermal annealing; Hall effect measure; optical band gaps; UV-visible-NIR spectroscopy; photodegradation

\section{Introduction}

Certain transition metal oxynitrides are known photocatalysts capable of water splitting by the energy of photons in the range of visible light [1-3]. The photocatalytic function relies on two material characters; one is the multivalence of the metallic element which is intrinsic to transition-metals, and the other is hybridized orbitals between metals and oxygen or nitrogen to provide intra-bands between valance and conduction bands. Much more like doping processes, these intra-bands not only provide alternative paths for electrons to change their states but also serve as stepstones to the conduction band. If prudently articulating this mechanism, the electron-hole pair can be effectively separated and followed by further immediately available proximate photochemical reactions.

From an engineering point of view, transition metal oxynitrides can be apt photocatalysts only under given optimal compositions and microstructures. Another feature of transition metal oxynitrides is their good corrosive resistance because of the stable microstructures maintained by the coexistence of nitrides and oxides [1-3]. This is an additive favorite for oxynitrides as catalysts without compromising integrity in harsh conditions. In general, oxynitrides are more stable under atmospheric and aqueous conditions when compared to pure nitrides due to the presence of oxide phases. This feature provides 
an advantage for applications that require continuous operations under oxidative environments or submersion in aqueous solutions, such as water splitting or environmental treatment [1]. Metal oxynitrides are also mechanically stronger than pure oxides because of denser structures packed by nitrides [4-6].

The optical band gaps in many transition-metal oxynitrides are narrower than those of pure oxides [1,3,7-11]. For example, the generic band gap of $\mathrm{TiO}_{2}$ is $\sim 3.2 \mathrm{eV}$, which corresponds to $\sim 387 \mathrm{~nm}$ wavelength, while an $\mathrm{N}$-doping of $\mathrm{TiO}_{2}$ has a bandgap reduced from the ultraviolet into the visible region $(<3.1 \mathrm{eV}$, of wavelength $399.95 \mathrm{~nm})$ ready for photocatalysis [12-15]. The smaller bandgap makes transition metal oxynitrides electronically and optically advantageous. Moreover, for materials to be practically useful, these oxynitrides usually have high valences in the $\mathrm{d}^{0}$ orbital configuration in order to have copious electrons available, leading to some unique electrical, optical, or even magnetic properties. Such a setting also characteristically forms the crystal structure of $\mathrm{AB}\left(\mathrm{N}_{x} \mathrm{O}_{3-x}\right)$, where both $\mathrm{A}$ and $\mathrm{B}$ are transition metals. Examples of these oxynitrides are $\mathrm{LaTaON}_{2}$ and $\mathrm{BaTaO}_{2} \mathrm{~N}$, just to name a few [8,16-19].

More particulars about the optical band gap in transition metal oxynitrides are briefly discussed here. Since oxygen is more electronically negative than nitrogen $\left(\mathrm{O}_{2}\right.$ : $\left(\sigma_{2 s}\right)^{2}\left(\sigma_{2 s}^{*}\right)^{2}\left(\sigma_{2 p}\right)^{2}\left(\pi_{2 p}\right)^{4}\left(\pi_{2 p}^{*}\right)^{2}$ vs. $\left.\mathrm{N}_{2}:\left(\sigma_{2 s}\right)^{2}\left(\sigma_{2 s}^{*}\right)^{2}\left(\sigma_{2 p}\right)^{2}\left(\pi_{2 p}\right)^{4}\right)$, the energy level of hybrid orbitals between transition metals and oxygen is lower than that between metals and nitrogen. This affects the valance bands in pure oxides to be lower as compared to those in pure nitride. The lower valance band thus leads to a larger bandgap as the valance band is anion-based (O or $\mathrm{N}$ dominant), while the conduction band is cation-based (metal dominant). Therefore, introducing nitrides in pure oxides (nitridation) can be a viable approach to reduce the typical wide bandgaps in oxides. The narrower bandgap is also a prerequisite for photocatalytic function in the range of visible light region $(\lambda=400-700 \mathrm{~nm})$.

However, from the manufacturing aspect, nitridation on oxides is a more demanding process that usually requires high temperature or pressure with a large supply of nitrogen because oxides are chemically much more stable than nitrides. On the contrary, with a much smaller amount of oxygen, oxidation of nitrides is a more viable and precise way to create oxynitrides as the chemically active characters of oxygen. It is also important to remember that the photocatalytic function critically relies on the delicate ratio of microstructures between nitrides and oxides [20-26].

In this study, we deposited tantalum oxynitride films by sputtering under fixed nitrogen $(10 \mathrm{sccm})$ and variable oxygen flow rates $(0-4 \mathrm{sccm})$. Tantalum is a rare transition metal and is highly corrosion-resistant due to its chemical inertness. It is also a refractory metal with a melting point of $3290 \mathrm{~K}\left(3017^{\circ} \mathrm{C}\right)$. Tantalum belongs to the d-block group in the periodic table and is of multivalence with possible oxidation states of $-3,-1,+1,+2$, $+3,+4$, and +5 (naturally stable state) $[27,28]$. All these properties are compatible with the purpose of photo-catalysis.

To have crystalline films, rapid thermal annealing was further carried out after deposition to form crystalline tantalum oxynitride. The material characterizations on films include X-ray diffraction (XRD) for identifying crystal structures in annealed films, scanning electron microscope (SEM) for observing surface morphologies, energy-dispersive X-ray spectroscopy (EDS) for checking surface elemental compositions, Raman Spectroscopy for identifying vibrational modes in crystal structures, four-point probe, and Hall effect analyzer for evaluating electrical conductivity, and UV-visible-NIR spectrometer for the optical absorption and transparency. Optical band gaps of deposited films were numerically estimated using the Tauc plot based on UV-visible-NIR spectroscopy. After the aforementioned characterizations, the photodegradation efficiency of selected films was tested against methyl orange in de-ionized (DI) water under continuous exposure to visible light for a prolonged period. 


\section{Experiment}

The tantalum oxynitride thin films are deposited by sputtering on quartz glass $\left(20 \mathrm{~mm} \times 20 \mathrm{~mm} \times 0.7 \mathrm{~mm}\right.$, for optical measurements) or Si wafer ( $\phi 4^{\prime \prime}$, p-type, $20 \mathrm{~mm} \times 20 \mathrm{~mm} \times 0.5 \mathrm{~mm}$, for material characterizations). Details of sputtering and measurement of films shall be discussed in the following. The experimental outline and parameters of sputtering are presented in Figure 1 and Table 1, respectively, for readers' reference.

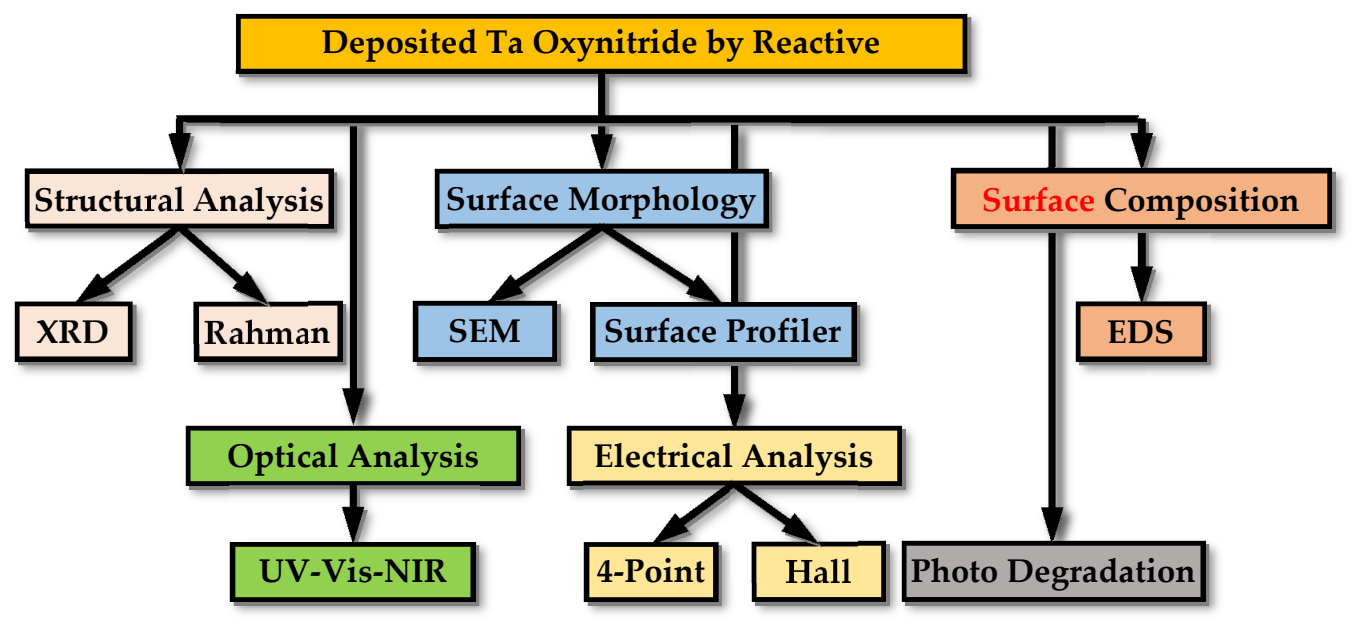

Figure 1. Experimental procedure and plan.

Table 1. Parameters for PVD and rapid thermal annealing process.

\begin{tabular}{|c|c|}
\hline \multicolumn{2}{|c|}{ Sputtering } \\
\hline Parameter & Set Value \\
\hline Target power $(\mathrm{W})$ & DC 190 \\
\hline Target composition & Ta (99.9999 wt.\%) \\
\hline Background pressure $(\mathrm{Pa})$ & $6.4 \times 10^{-4}$ \\
\hline Working pressure $(\mathrm{Pa})$ & $0.87-0.93$ approx. \\
\hline Substrate temperature $\left({ }^{\circ} \mathrm{C}\right)$ & Room temperature \\
\hline Target-substrate distance $(\mathrm{cm})$ & 10 \\
\hline Substrate bias (V) & 0 \\
\hline $\mathrm{O}_{2}$ flow rate $(\mathrm{sccm})$ & $0,0.13,0.25,0.38,0.5,0.75,1,1.5,2,4$ \\
\hline Ar flow rate $(\mathrm{sccm})$ & 20 \\
\hline $\mathrm{N}_{2}$ flow rate $(\mathrm{sccm})$ & 10 \\
\hline \multicolumn{2}{|c|}{ Annealing } \\
\hline Parameter & Set Value \\
\hline Temperature $\left({ }^{\circ} \mathrm{C}\right)$ & 800 \\
\hline Time (min) & 5 \\
\hline Ar flow rate $(\mathrm{sccm})$ & 5000 \\
\hline
\end{tabular}

\subsection{Substrate Preparation}

A 4" silicon wafer (p-type, $<100>$ ) was first cut into $20 \mathrm{~mm} \times 20 \mathrm{~mm}$ pieces using a diamond scribe. The cut substrate was etched in buffered oxide etchant (6:1 volume ratio of $40 \% \mathrm{NH}_{4} \mathrm{~F}$ in water to $49 \%$ of $\mathrm{HF}$ in water) for $20 \sim 30$ seconds to remove silicon dioxide $\left(\mathrm{SiO}_{2}\right)$ or silicon nitride $\left(\mathrm{Si}_{3} \mathrm{~N}_{4}\right)$. After etching, the sample was ultrasonically cleaned following the sequence of de-ionized (DI) water, acetone (100\%), (DI) water, ethanol (95\%), and DI water, each lasting for 10 minutes. Finally, the substrates were blown dry in nitrogen (99.95\%).

For quartz glass (99.99\%, Ultimate Materials Technology Co., Ltd. Hsinchu, Taiwan), it was also cut into $20 \mathrm{~mm} \times 20 \mathrm{~mm}$ pieces using a diamond scribe. Then, the cut glass was ultrasonically cleaned by $\mathrm{KOH}(1 \mathrm{~g} / 100 \mathrm{ml}$ in water $)$ and the same sequence of the 
aforementioned solutions for 10 minutes each. Similarly, the substrates were blown dry in nitrogen $(99.95 \%)$.

\subsection{Film Deposition}

Tantalum targets (99.99 wt.\% Ultimate Materials Technology Co., Ltd. Hsinchu, Taiwan) and parameters used for the deposition of different films are listed in Table 1 . The PVD chamber before the deposition was vacuumed to $6.4 \times 10^{-4} \mathrm{~Pa}$ under room temperature for all depositions. The working gases for plasma were $20 \mathrm{sccm}$ Ar (99.999\%), $10 \mathrm{sccm} \mathrm{N}$ (99.999\%), and/or $\mathrm{O}_{2}(99.999 \%)$ at various flow rates. All gases were purchased from local suppliers. The flow rates of all gases were controlled by mass flow controllers installed at the outlet of gas tanks. All mass flow controllers were also purchased from local suppliers.

Direct current (DC) power of $190 \mathrm{~W}$ is supplied to the Ta target. No substrate bias is applied during deposition.

To clean up volatile contaminants on the target, we always pumped Ar into the chamber at first and maintained it for 10 minutes before the deposition. All other process parameters can be found in Table 1 without further elaboration.

Post-deposition annealing is carried out as follows. Ar is first pumped into the chamber at $5000 \mathrm{sccm}$ to purge the chamber for $30 \mathrm{sec}$. After the purge, the temperature was raised to $800^{\circ} \mathrm{C}$ for $5 \mathrm{~min}\left(\sim 13.33^{\circ} \mathrm{C} / \mathrm{s}\right)$ to anneal the sample under a continuous flow of Ar. When annealing is finished, the chamber was left open to cool down to $50{ }^{\circ} \mathrm{C}$ in approximately $40 \mathrm{~min}$, and then the sample was removed from the chamber for further tests or characterizations.

\subsection{Characterization}

\subsubsection{Thickness and Surface Morphology of Films}

Thicknesses of deposited films were evaluated by surface profiler (Surfcorder ET200, Kosaka, Japan). Before deposition, half of the substrate was masked by an oil marker. Then the maker was removed by alcohol to create a step profile before measuring the thickness of deposited films. The measurement was taken along five randomly selected lines on the sample surface across the edge of the deposited film. The average of these measured data was counted as the film thickness.

The surface morphology of deposition films was examined and imaged by scanning electron microscope (SEM, S-3400N, Hitachi, Japan). For operation, the voltage of the accelerated electron beam was set at $15 \mathrm{kV}$ and the magnification was chosen to be 3000 for the best resolution.

\subsubsection{Microstructure of Films}

The X-ray diffractometer (XRD, PANalytical XPert PRO MPD) with monochromatic high-intensity $\mathrm{Cu} \mathrm{K} \alpha$ radiation $(\lambda=1.5425 \AA)$ was used to determine the crystal structures of deposited films. The mode was set to thin-film, and the scanning angle was from $15^{\circ}-2 \theta$ to $80^{\circ}-2 \theta$, with a step size of $0.02^{\circ}$, measuring time of $0.5 \mathrm{~s}$ per step and incident angle $0.5^{\circ}$.

The crystal size of films $D$ can be calculated according to Scherrer's formula,

$$
D=\frac{k \lambda}{\beta \cos \theta}
$$

where $k$ is the shape factor (0.9), $\lambda$ the wavelength of X-rays $(1.5425 \AA), \theta$ the scattering angle of the crystal plane, and $\beta$ the full width at half maximum (FWHM) of the peak. The analysis was numerically calculated by Jade ${ }^{\circledR} 5$ (Materials. Data Inc., CA, USA).

The vibrational modes of microstructures were assessed by a Raman spectrometer (iHR 550, Horiba, Japan). To detect the spectra of Raman shifts, the excitation wavelength used was a $532 \mathrm{~nm}$ He-Ne laser $(80 \mathrm{~mW})$. Relevant peaks of Raman shift for different films are discussed later based on different resources from the literature. 


\subsubsection{Elemental Chemical Composition}

The chemical compositions of deposited films were examined by an energy-dispersive X-ray spectrometer (EDS, Bruker Nano, XFlash Detector 5010, Germany). The operating voltage and current were set to $15.0 \mathrm{kV}$ and $70.0 \mu \mathrm{A}$, respectively. The working distance was around $10 \mathrm{~mm}$. The target elements for EDS are nitrogen $(\mathrm{K} \alpha)$, oxygen $(\mathrm{K} \alpha)$, tantalum $(\mathrm{L} \alpha)$, and silicon ( $\mathrm{K} \alpha$, substrate). The size of areas for examination was around $40 \mu \mathrm{m} \times 30 \mu \mathrm{m}$.

\subsubsection{Electrical Measurement}

The electrical resistivity $(\Omega \mathrm{cm})$ of deposited films with known thicknesses was measured by a four-point probe (RT-70/RG-7, Naspon, Japan). The probe was placed on the center of samples and the measurement was repeated five times for each sample to record the averaged resistance.

To further evaluate other relevant electrical properties of deposited films such as carrier density, mobility, and Hall coefficient, we used a Hall-effect analyzer (AHM-800B, Advanced Design Technology, Taiwan) to assess the electrical properties of deposited films.

To validate both measurements, the electrical resistivity measured by the four-point probe and Hall-effect analysis were cross-examined with each other to avoid erroneous experimental results.

\subsubsection{Optical Measurement for Films}

The optical transmittance and reflectance of the films were measured by a UV-VIS-NIR double beam spectrophotometer (JASCO-V760, US) with wavelengths ranging from 200 to $1600 \mathrm{~nm}$. The optical absorption $A_{\text {film }}$ was calculated by subtracting transmittance $\left(T_{\text {film }}\right)$ and reflectance $\left(R_{f i l m}\right)$ of film from $100 \%$, i.e.,

$$
A_{\text {film }}=100 \%-T_{\text {film }}-R_{\text {film }}
$$

Each sample was measured 5 times in order to have a more accountable average optical absorption.

Optical band gaps of the deposited films were estimated from the spectra of transmittance and reflectance by UV-VIS-NIR spectrometer. The calculation procedure combined the Beer-Lambert law and the Tauc formula $[29,30]$. The Beer-Lambert law states that optical transmittance decays exponentially through the thickness of film [31], i.e.,

$$
T=\exp (-\alpha d)
$$

where $\alpha$ and $d$ are absorption coefficient and thickness of film, respectively. Here, zero optical absorption of the substrate is assumed. On the other hand, the Tauc formula gives the electron transition across parabolic/square root of energy bands as

$$
(\alpha E)^{x}=B\left(E-E_{g}\right)
$$

where $E=h c / \lambda$ is the incident photon energy, $E_{g}$ is Tauc bandgap, and $B$ is microstructure related constant called Tauc parameter, which represents the slope of the linear part of the curve in the plot of $(\alpha E)^{x}$ against $E[29,30]$. Different numerical values of the exponent $x$ characterize different schemes of electron transition at the edge of optical absorption between UV and visible light. $x=1 / 2$ is commonly thought to be a good description for indirect transitions, particularly inside amorphous structures where random structures make the indirect transitions most likely to happen $[29,30,32-36]$. On the other hand, $x=2$ usually indicates direct band gap transitions when electrons' momentum is largely conserved [29,30,32-36].

\subsubsection{Photodegradation Test}

The photodegradation by selected annealed tantalum oxynitride films under visible light was further tested against the methyl orange solution. This test was set up as follows. 
Tantalum oxynitride sample films were immersed in the solution of $40 \mathrm{ppm}$ methyl orange $\left(\mathrm{C}_{14} \mathrm{H}_{14} \mathrm{~N}_{3} \mathrm{NaO}_{3} \mathrm{~S} \cdot \mathrm{xH}_{2} \mathrm{O}\right.$, Wako Pure Chemical Corporation, Japan) in de-ionized water under irradiation of visible light (Solar Simulator, MFS-PV-Basic, Hong-Ming Tech, Taiwan). The testing period lasted for $6 \mathrm{~h}$. During the test, three methyl orange solutions at different times $(0,3$, and $6 \mathrm{~h}$ ) were sampled out for measuring their optical density (absorption) by UV-Vis-NIR spectrometer (JASCO-V670, US). The major absorption peak of methyl orange was centered around $480 \mathrm{~nm}$, which represents the residual amount of methyl orange in solution. The absorption is quantified as

$$
\log _{10}(A)=\log _{10}(100)-\log _{10}(T)=2-\log _{10}(T)
$$

where $A$ and $T$ are optical absorbance (\%) and transmittance (\%), respectively. For the purpose of comparison, we present results of degradation in terms of the ratio of absorption defined as

$$
\text { Absorption Ratio }=A_{\text {solution with sample }}(t) / A_{\text {solution without sample }}(t)
$$

This ratio should be less than one if the decomposition of methyl orange does occur in the solution. A higher ratio indicates a higher residual concentration of methyl orange in solution and thus a lower degree of degradation by the oxynitride film.

\section{Results}

\subsection{Average Deposition Rate}

The average deposition rates and thickness of different films are shown in Figure 2 where the average deposition rate initially increases from $11.05 \mathrm{~nm} / \mathrm{min}$ under $0 \mathrm{sccm}$ oxygen to a maximum of $16.33 \mathrm{~nm} / \mathrm{min}$ at $2 \mathrm{sccm}$ oxygen. Then, the average deposition rate declines as the oxygen supply increases. It decreases to $10.95 \mathrm{~nm} / \mathrm{min}$ at $4 \mathrm{sccm}$ oxygen. The initial increase of deposition rate can be attributed to the formation of less dense oxynitrides or oxides, which rapidly thicken the deposited film. While the subsequent decrease is related to the poisoning of Ta target by oxygen, this makes the chamber plasma less conductive and thus lower deposition rates.

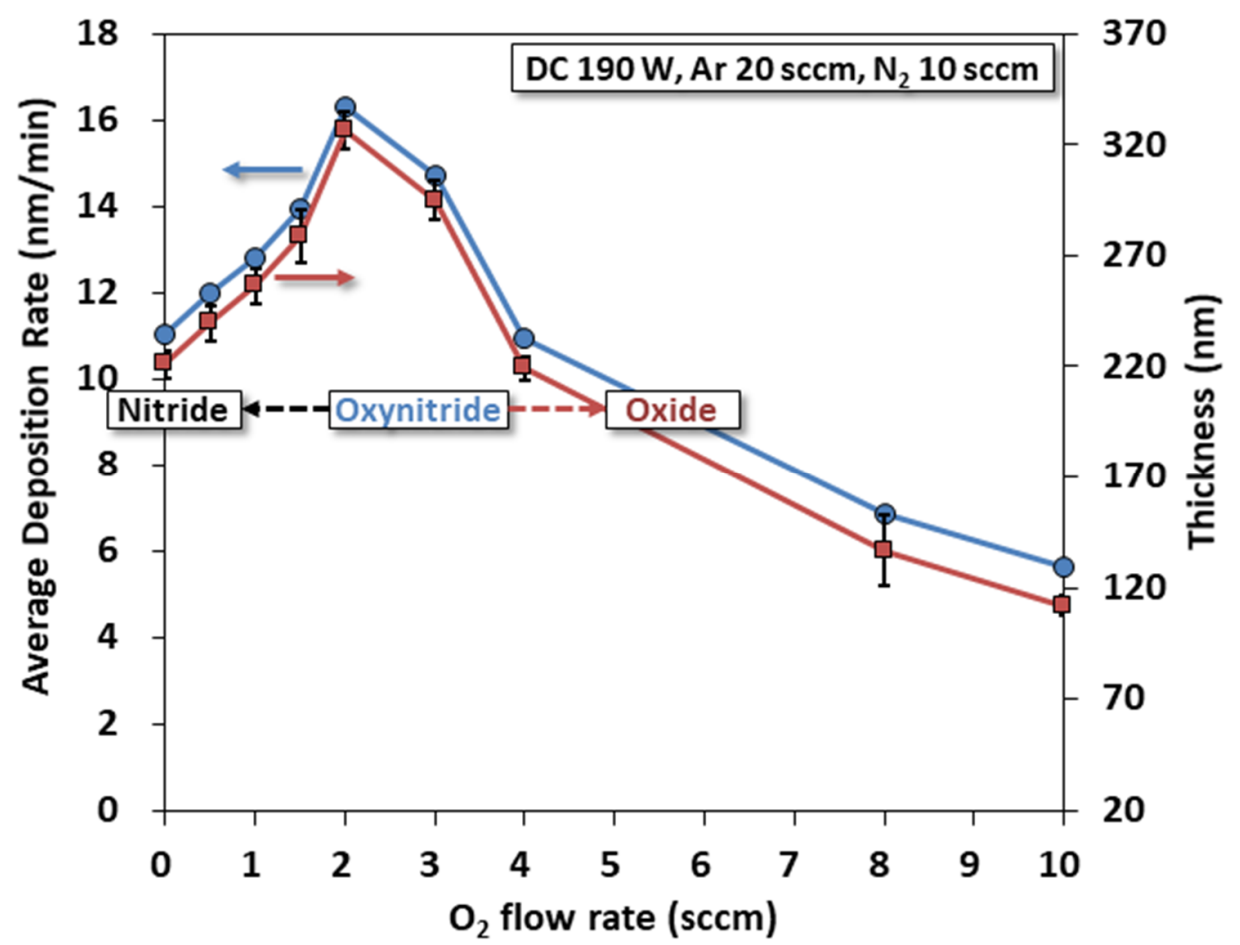

Figure 2. The average deposition rate and thickness of deposited films. 
For all material characterizations in the following sections, we choose $200 \mathrm{~nm}$ as the target thickness to deposit films. The time for deposition then was estimated based on the average deposition rates in Figure 2.

\section{2. $X R D$}

The XRD pattern of annealed films is shown in Figure 3. For zero oxygen flow, sample after annealed, only TaN were found by Gaussian fit using Jade ${ }^{\circledR} 6.5$. The peaks for TaN are $(1,2,1),(0,0,2),(3,1,2),(5,0,1)$, and $(2,4,2)$ (TaN, ICCD PDF $49-1283)$. The $(1,2,1)$ crystal plane has the highest intensity with an estimated crystal size of $83.6 \AA$. For oxygen flow to increase to higher than $0.25 \mathrm{sccm}$, the oxynitride starts to form. Gaussian fit yields very complicated crystal structures with a large number of crystal planes (TaON, ICCD PDF 70-1193 and 71-0178) [37,38]. The signature peaks for tantalum oxynitrides are $(-1,1,1)$, $(1,1,1)$, and the tri-peaks are $(0,0,2),(0,2,0),(2,0,0)$. As the oxygen flow increases to more than $1.5 \mathrm{sccm}$, tantalum oxynitrides are replaced by tantalum oxides due to the much higher chemical reactivity of oxygen than that of nitrogen. However, this kind of replacement is also aided by high-temperature annealing, which transforms the sample film into complex oxides indicated by the larger number of fitted crystal planes. The three major peaks of the tantalum oxides were found to be $(0,0,1),(2,0,0)$, and $(2,0,1)\left(\mathrm{Ta}_{2} \mathrm{O}_{5}\right.$, PDF 71-0639) for all sample films deposited under oxygen flow rate exceeding $1.5 \mathrm{sccm}$.

Oxynitrides cannot be totally separated from oxides or nitrides. For example, the tantalum oxynitrides $(-1,1,1)$ and $(2,0,0)$ crystal planes almost overlap those in the oxides $(2,0,0)$ and $(2,0,1)$, respectively. This is in line with the nature of oxynitrides, which are tri-elemental complex compounds of properties in between pure nitrides and oxides.

The estimated crystal sizes of selected crystal planes are listed in the Table A1 in Appendix A.

It is worth noting that the color of annealed films is changed according to different oxygen flow rates. For the lower $\mathrm{O}_{2}$ flow rate $(\sim 0.5 \mathrm{sccm})$, the film has a dark brown color. The color becomes more yellow and transparent when the $\mathrm{O}_{2}$ flow rate reaches $\sim 1.0 \mathrm{sccm}$. When the $\mathrm{O}_{2}$ flow rate increases to $1.5 \mathrm{sccm}$, the film appears lighter green and even more transparent. As the $\mathrm{O}_{2}$ flow rate exceeds $2 \mathrm{sccm}$, the sample films all become transparent. This color change serves as an important indicator for the transformation of microstructure and associated optical properties, which are discussed below.

\subsection{EDS}

The elemental chemical compositions of annealed films in the selected surface areas under SEM are shown in Figure 4. SEM images accompanied with the EDS are provided in the supplementary section for readers' reference. The most important observation from EDS is that the atomic percentage of $\mathrm{O}$ is increased $(0-\sim 65 \%)$ and $\mathrm{N}$ decreased $(\sim 63 \%-13 \%)$, correspondingly, by the increased oxygen supply. The amount of Ta also reduces $(\sim 37 \%-$ $22 \%$ ) but more marginally. This trend directly reflects the change of chemical compositions on the surface of films according to the change of oxygen supply.

Although it is commonly recognized that EDS is not an accurate measurement for the chemical composition, it is undeniable that EDS is a useful reference to show the changes of elemental compositions according to different oxygen flow rates. With further calculations on the $\mathrm{O} / \mathrm{N}$ ratio from EDS, we found that this ratio increases significantly $(0.77$ at $\mathrm{O} 2$ : $1.0 \mathrm{sccm}-4.31$ at $\mathrm{O}_{2}: 2 \mathrm{sccm} 1.45$ at $\mathrm{O} 2: 1.5 \mathrm{sccm}-4.31$ at $\left.\mathrm{O}_{2}: 2 \mathrm{sccm}\right)$. A reference milestone is between 1.0 and $1.5 \mathrm{sccm}$, at which the $\mathrm{O} / \mathrm{N}$ ratio exceeds unity. This also implies that tantalum oxides become a major phase for oxygen flow rate higher than $2 \mathrm{sccm}$. This change is close to results from the XRD pattern in which the oxides are clearly present in the film for oxygen flow rate exceeding $2 \mathrm{sccm}$. The substantial formation of tantalum oxides has a critical impact on the electrical and optical properties of the annealed films as discussed in the following sections. 

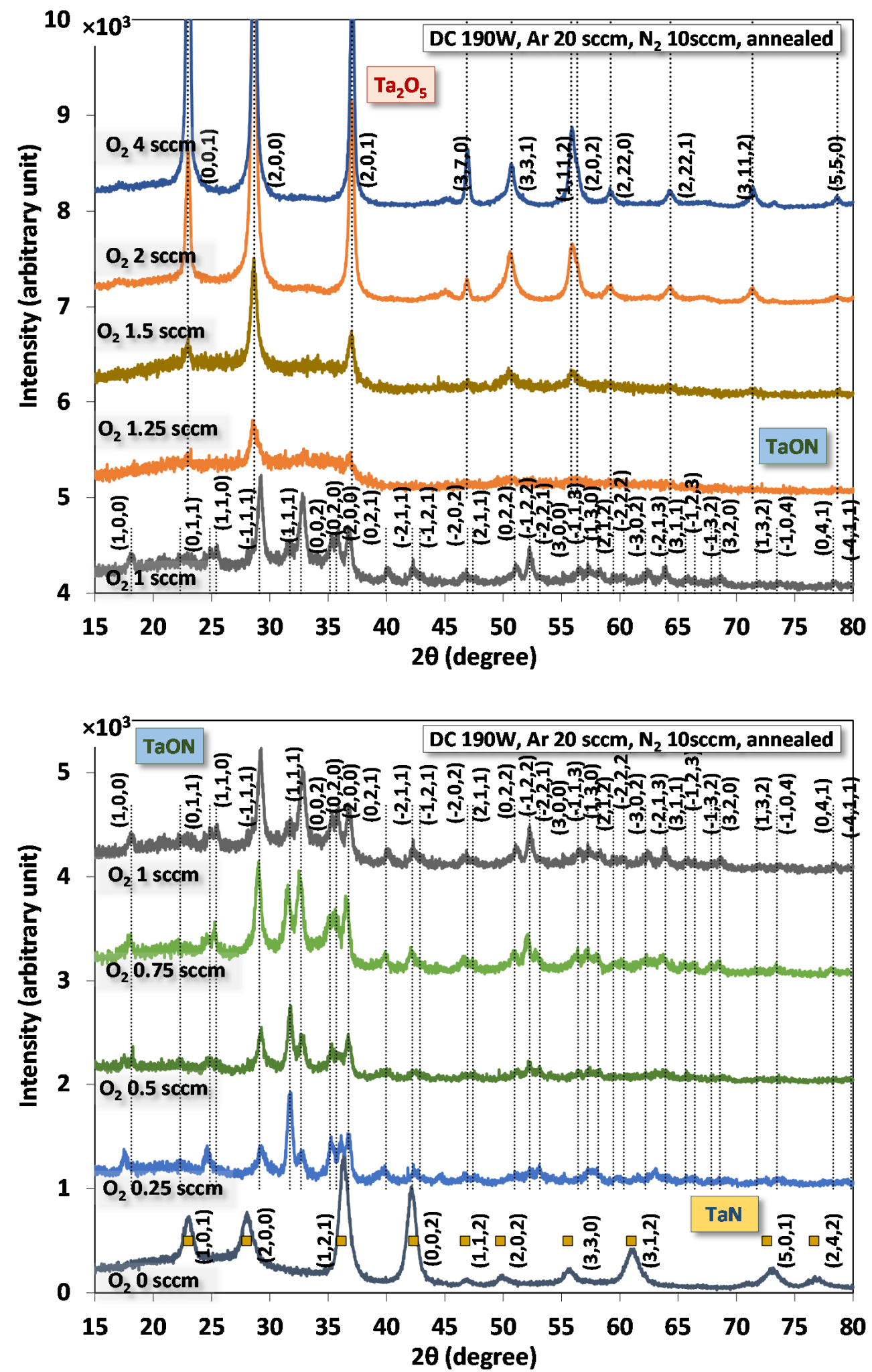

Figure 3. XRD patterns of annealed films deposited under different oxygen flow rates. 


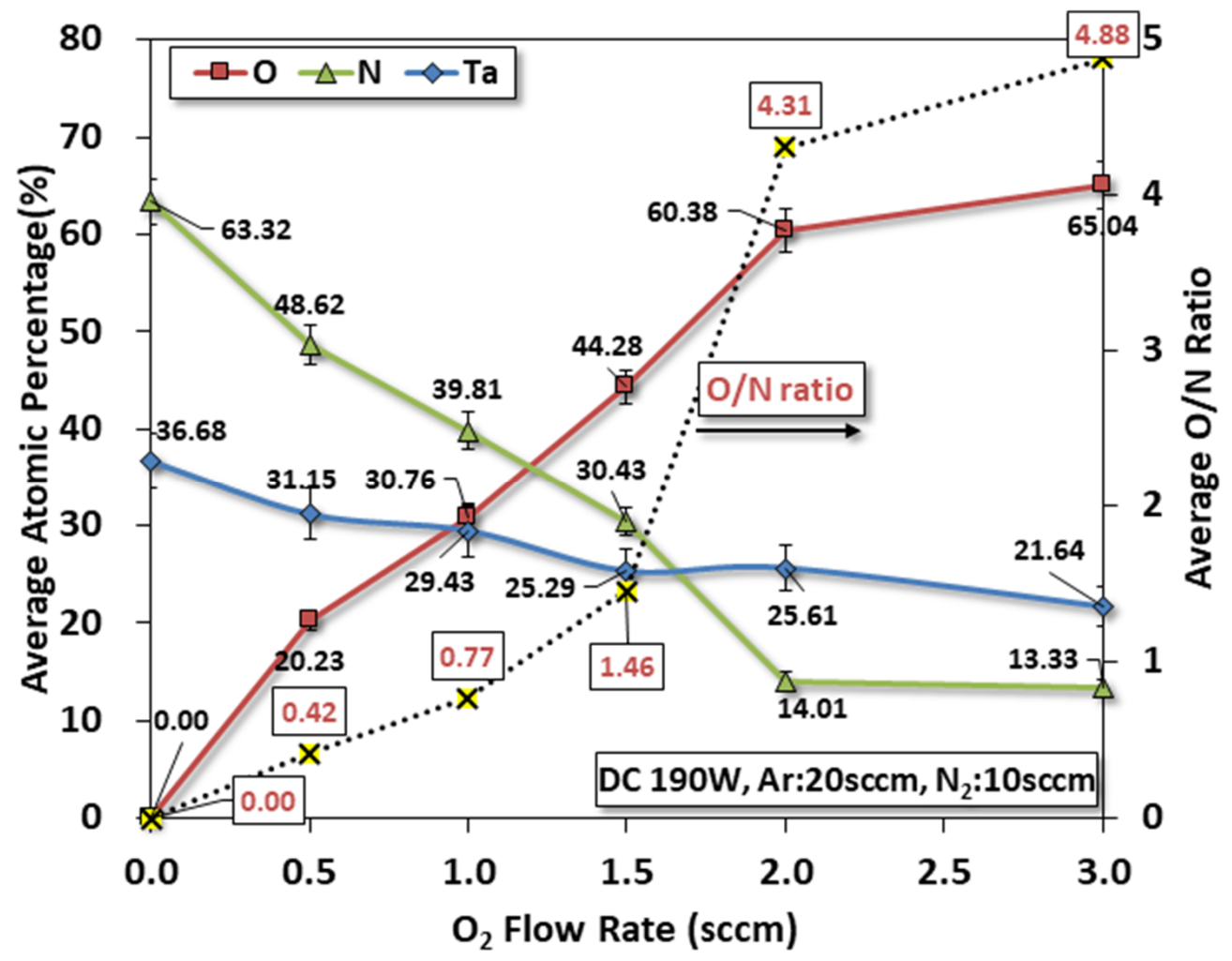

Figure 4. Estimated elemental compositions from EDS of annealed films under different oxygen flow rates.

\subsection{Raman Spectra}

The Raman spectra of annealed films are shown in Figure 5 where peaks were numerically fitted by Gaussian functions. The vibrational modes of these peaks are listed in Table 2 with references. For annealed films deposited between 0.25 and 1.25 sccm, crystalline oxynitrides $(\beta-\mathrm{TaON})$ can be determined. This is accordant with findings in XRD. For the sample film of 1.5-sccm oxygen flow rate or higher, the Raman shift peaks for $\mathrm{Ta}_{2} \mathrm{O}_{5}$ are difficult to be identified because they are gravely shadowed by the vibrational modes of the $\mathrm{SiO}_{2}$ substrate. Note that the film is about $200 \mathrm{~nm}$ thick while the substrate is around several mm. Disentangling peaks of $\mathrm{Ta}_{2} \mathrm{O}_{5}$ from those of $\mathrm{SiO}_{2}$ thus becomes infeasible in the current dataset.

Table 2. Possible peaks in Raman spectra for tantalum oxynitride and silicon oxides (substrate).

\begin{tabular}{cccc}
\hline Wavenumber $\left(\mathbf{c m}^{-\mathbf{1}}\right)$ & Mode & Description & Reference \\
\hline 131.5 & $\mathrm{Ag}$ & $\beta-\mathrm{TaON}$ vibration & {$[39-41]$} \\
143.8 & $\mathrm{Ag}$ & $\beta-\mathrm{TaON}$ vibration & {$[39-41]$} \\
183.8 & $\mathrm{Ag}$ & $\beta-\mathrm{TaON}$ vibration & {$[39]$} \\
207.0 & $\mathrm{Ag}$ & $\beta-\mathrm{TaON}$ vibration & {$[40,41]$} \\
257.6 & $\mathrm{Bg}$ & $\beta-\mathrm{TaON}$ vibration & {$[39,40]$} \\
419.7 & $\mathrm{Ag}$ & $\beta-\mathrm{TaON}$ vibration & {$[39]$} \\
$350 \sim 450$ & & $\mathrm{v}-\mathrm{SiO} 2$ Bond bending & {$[41]$} \\
495 & & $\mathrm{v}-\mathrm{SiO} 2 \mathrm{D} 1$ & {$[41]$} \\
606 & $\mathrm{Ag}$ & $\beta-\mathrm{TaON}$ vibrations & {$[41]$} \\
652.9 & $\mathrm{Bg}$ & $\beta-\mathrm{TaON}$ vibrations & {$[39]$} \\
735.6 & & $\mathrm{v}-\mathrm{SiO} 2$ Tetrahedral & {$[41]$} \\
$780 \sim 850$ & & &
\end{tabular}




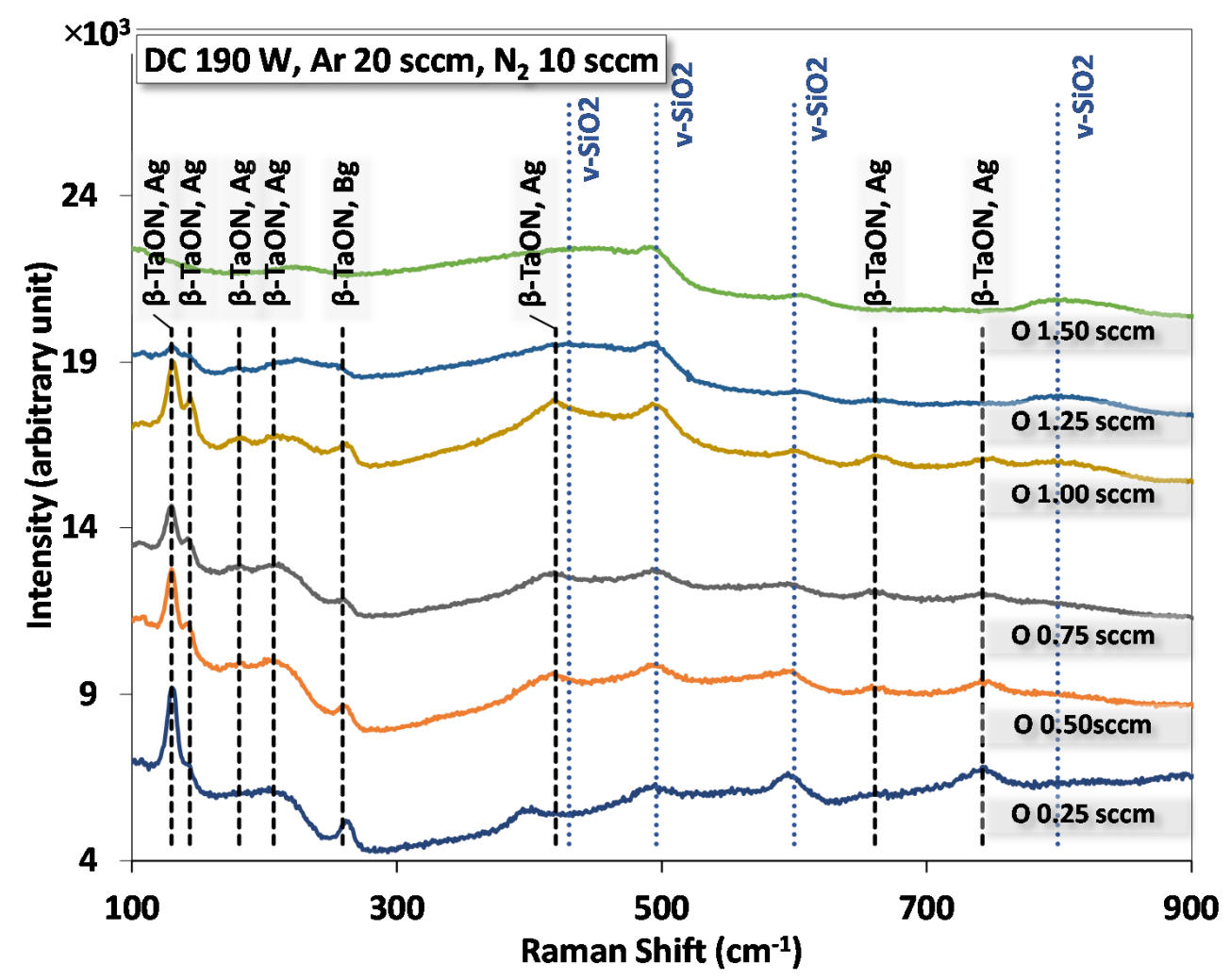

Figure 5. Raman spectra of annealed films under different oxygen flow rates.

Since the Raman spectroscopy determines the vibrational modes of chemical bonds based on the changes of molecular polarization by laser, the fitting result from Raman spectra accompanied with what was found in XRD and EDS provide evidence that (i) the oxynitride is $\beta$-TaON and (ii) oxynitrides are formed by oxygen flow from $\sim 0.25$ to $\sim 1.5 \mathrm{sccm}$.

\subsection{Electrical Resistivity}

The electrical resistivity of annealed films is shown in Figure 6, where resistivities are measurable only for films deposited under oxygen supply up to $1.0 \mathrm{sccm}$. We note that the resistivity of deposited films measured by the four-point probe and the Hall effect analyzer are close to each other, which can be viewed as cross-validation of both experimental measures.

Note that there is a limit of the measurement for both devices because the thickness of films is about $200 \mathrm{~nm}$, and the measurement takes on the resistance $R$ via the relation $R=\rho(l / A)$ to calculate resistivity $\rho$. If films are thicker (larger cross-sectional area $A$ ), then the limit of measurement can be higher.

The resistivity of deposited films is increased by more than three orders following the increase of oxygen flow rate from 0 to $1.0 \mathrm{sccm}$. This is due to the elevated oxygen content in films such that films change from tantalum nitrides (semi-conductive) to tantalum oxides (almost insulator) during deposition. Meanwhile, the lowered density of charge carriers for $\mathrm{O}_{2}$ higher than $0.25 \mathrm{sccm}$ also raises the electrical resistivity of films significantly.

The electrical resistivity is a benchmark test for a transition of the semi-conductor to the insulator. For oxynitrides with desired photo-catalytical function, we preferred more semi-conductive materials with an appropriate width of bandgaps, which can support electron-hole separation without immediate recombination after optical irradiation. Based on this electrical measure, films deposited under $0.25 \mathrm{sccm}$ or higher can be candidates for the photodegradation test. 


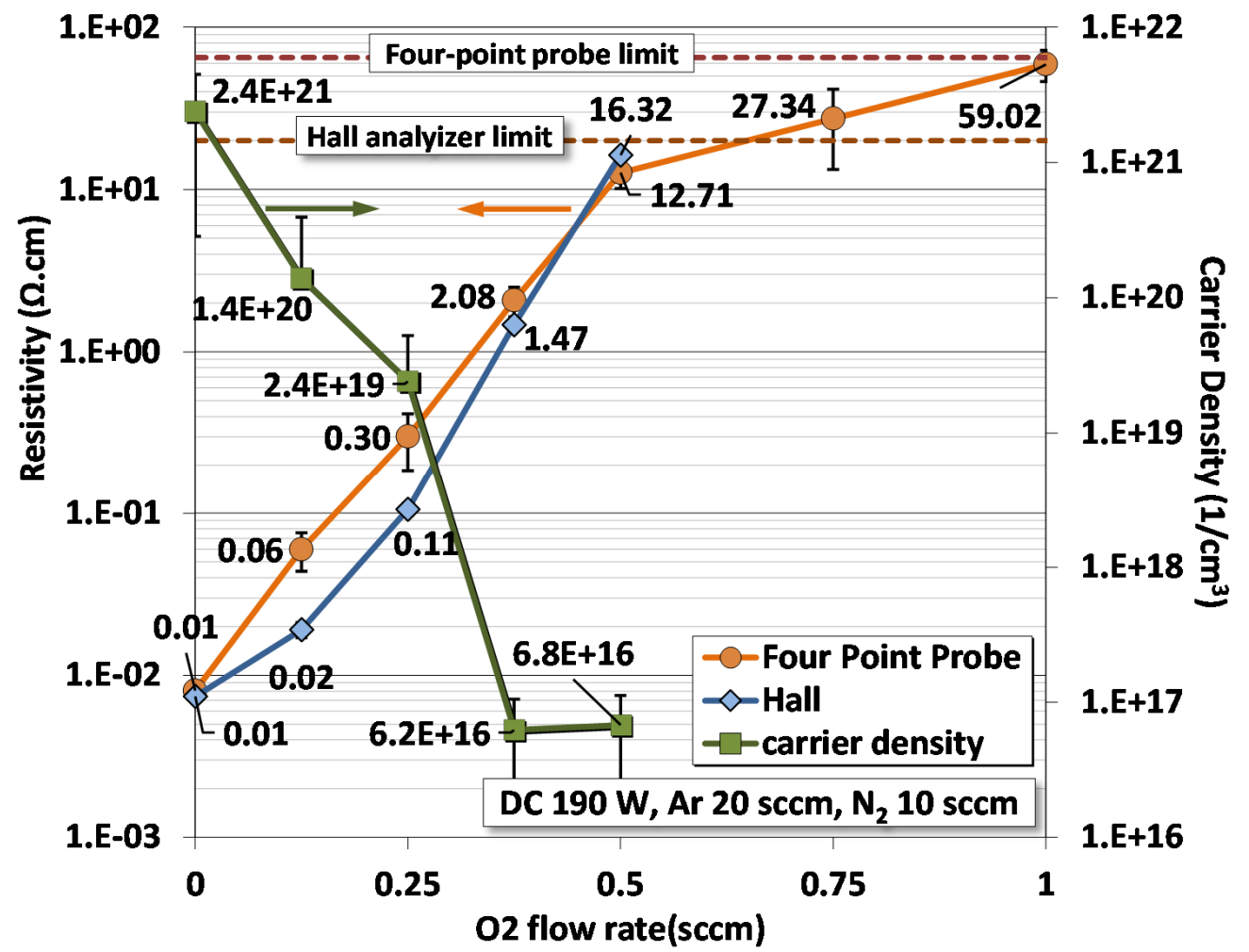

Figure 6. Electrical resistivity and carrier density of annealed films under different oxygen flow rates.

\subsection{UV-Vis-NIR Spectra}

The UV-Vis-NIR spectra of various films deposited under different oxygen flow rates are shown in Figure 7, where optical transmittance, reflectance, and absorbance are presented over the range of $200-900 \mathrm{~nm}$. There are several features found from these spectra:

- For zero oxygen supply, the tantalum nitride film is almost opaque with very low transmittance. The optical reflectance is between 30 and $40 \%$, and the absorbance reaches $60-90 \%$.

- As the oxygen supply increases from $0.5 \mathrm{sccm}$ to $2 \mathrm{sccm}$, the transmittance also increases in the range of visible light. This result implies a gradually increased transparency of the films. Associated with this increase, there are "shoulders" in the variation of transmittance when light changes from the UV to visible light. Just like doping in semi-conductors, these shoulders indicate a possible existence of intra-bands in the films.

- When the oxygen supply exceeds $2 \mathrm{sccm}$, the transmittance reaches above $80 \%$ in the range of visible light, while the absorbance reduces simultaneously to very low values. The switch between high and low transmittance and absorbance occurs around $300 \mathrm{~nm}$. In other words, films become transparent in visible light. This also shows that these high-oxygen films are effective filters for UV light.

- The color change of films is discussed in the section on XRD, and this change is in accordance with the variation of transmittance as shown in the inset of the photo.

- Note that certain degrees of transparency with sufficient optical absorbance are a necessity for oxynitride films to achieve photocatalysis. 

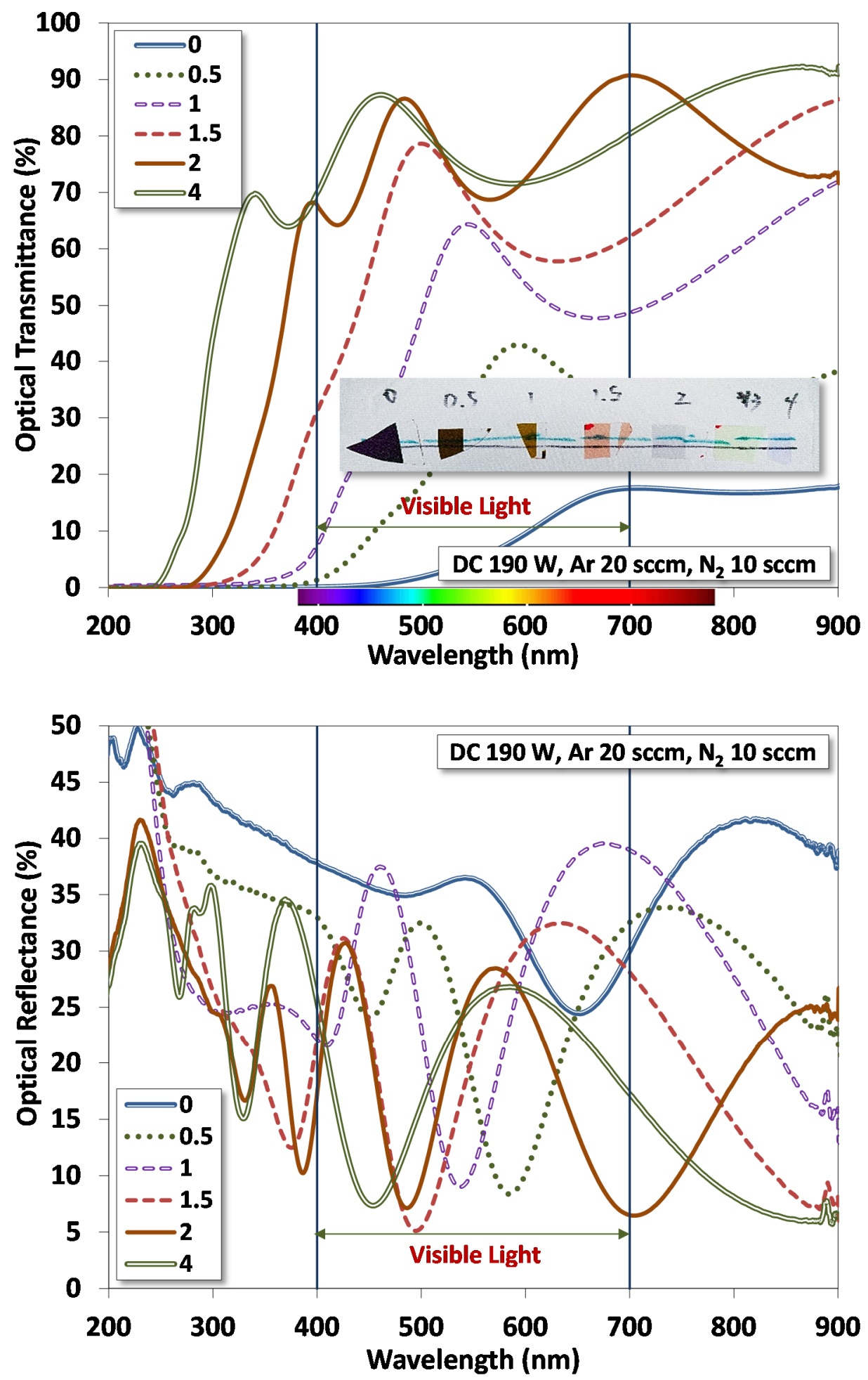

Figure 7. Cont. 


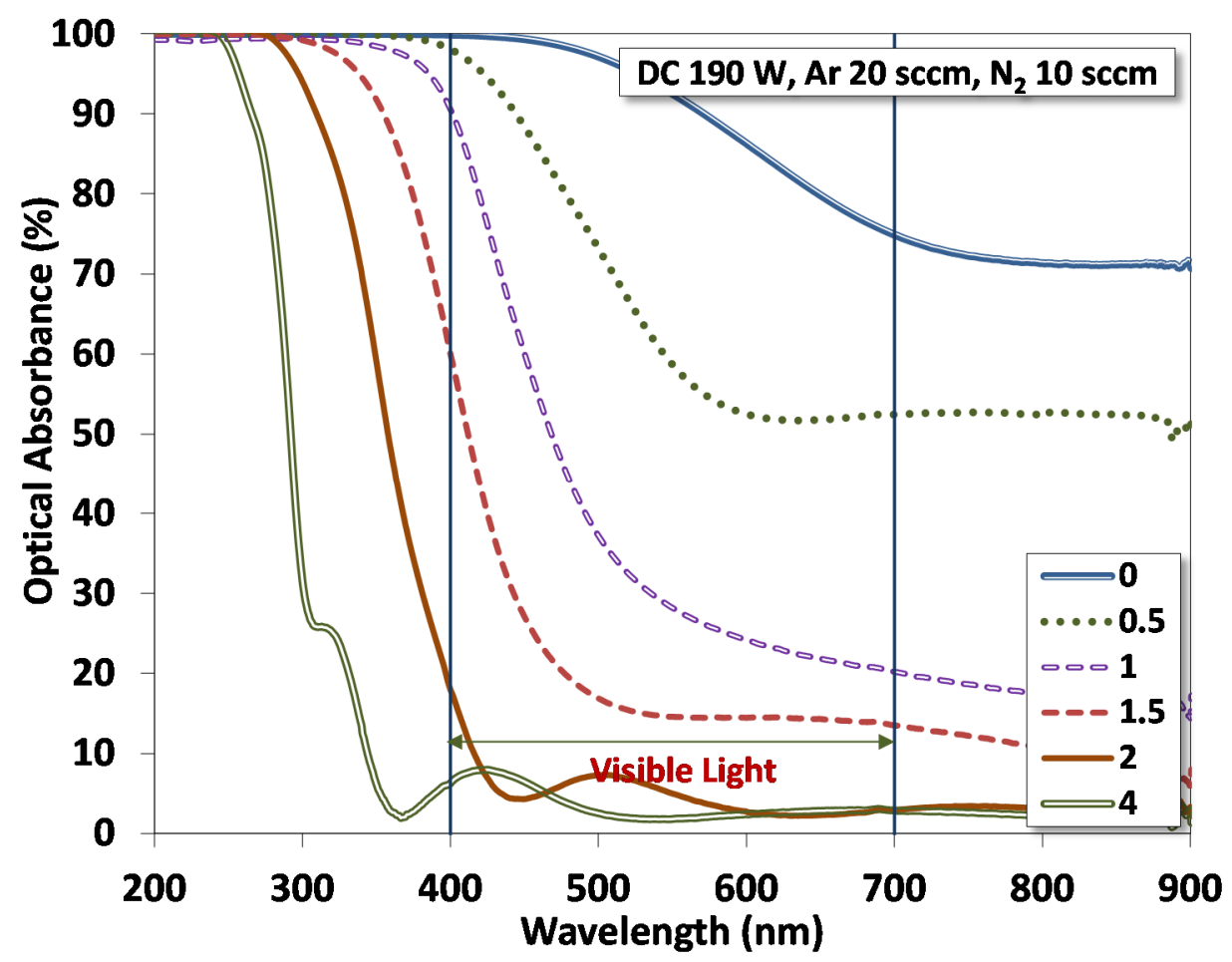

Figure 7. UV-Visible-NIR absorbance spectra of annealed films under different oxygen flow rates.

\subsection{Optical Band Gap}

Using Equations (3) and (4) and the data from UV-VIS-NIR spectra, we can calculate the optical bandgaps of the annealed films. Figure 8 presents the estimated results for annealed films deposited under different oxygen flow rates. Four samples of calculation using the Tauc plot are also shown in the insets. As seen from the figure, when the $\mathrm{O}_{2}$ supply falls between 0.5 and $2.0 \mathrm{sccm}$, there exist two bands with a high energy level band between 2.6 and $3.2 \mathrm{eV}$, and a lower level one around $0.8-1.1 \mathrm{eV}$. The difference between these two bands is around 1.8-2.1 eV. Such a tandem combination provides an effective structure for the photocatalytic function as electrons can fully utilize the photon energy in the range of visible light to change their states from the valance band to the conduction band.

When $\mathrm{O}_{2}$ supply exceeds $2.0 \mathrm{sccm}$, the energy level of both bands is simply too high for electrons to reach even if UV energy is provided. This also explains why films become transparent at a higher $\mathrm{O}_{2}$ flow rate as mentioned earlier.

Based on results from XRD, EDS, Raman, electrical resistivity, UV-Vis-NIR spectra, and estimated optical band gaps, we could comfortably select films deposited under 0.5 , 1.0 , and $1.5 \mathrm{sccm} \mathrm{O}_{2}$ flow for the photodegradation test in the next section because these films are almost certainly oxynitrides.

\subsection{Photodegradation Test}

The results of photodegradation against the methyl orange in DI water are shown in Figure 9. We present results using the ratio of absorption as defined in Equation (6) for different exposure times up to $6 \mathrm{~h}$. In all samples, the methyl orange was decomposed as time elapsed. Nevertheless, annealed films deposited between 0.25 and $1.25 \mathrm{sccm}$ have higher efficiency on the degradation of methyl orange. This may be attributed to the sufficient quantity of oxynitrides in the film by the higher $\mathrm{O}_{2}$ supply. Since the methyl orange is quite stable even under long-term exposure to solar light, this test demonstrates the feasibility of photodegradation by tantalum oxynitrides under mildly visible light irradiation. 


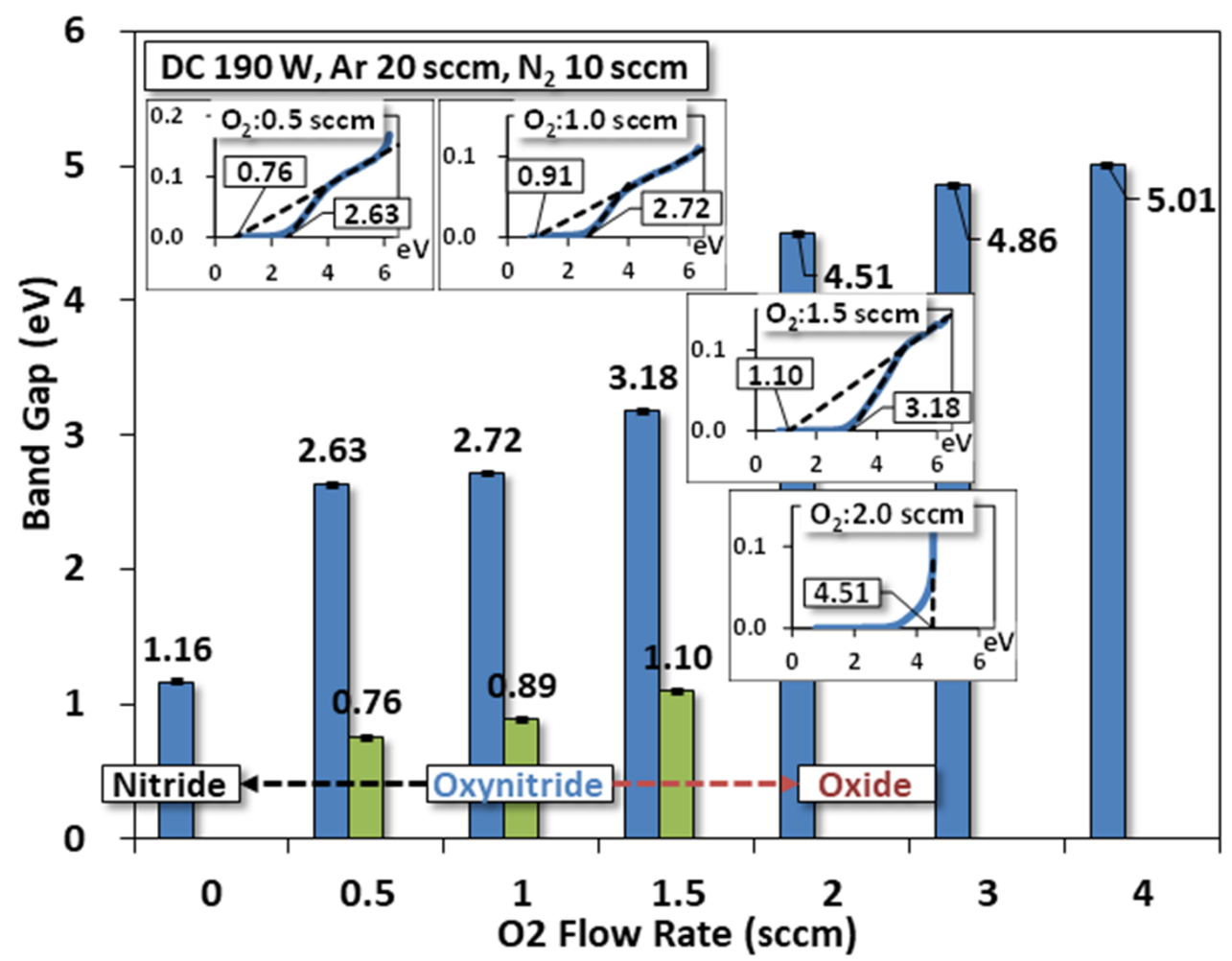

Figure 8. Estimated optical band gaps in annealed films based on the UV-Visible-NIR spectra using the Tauc plot.

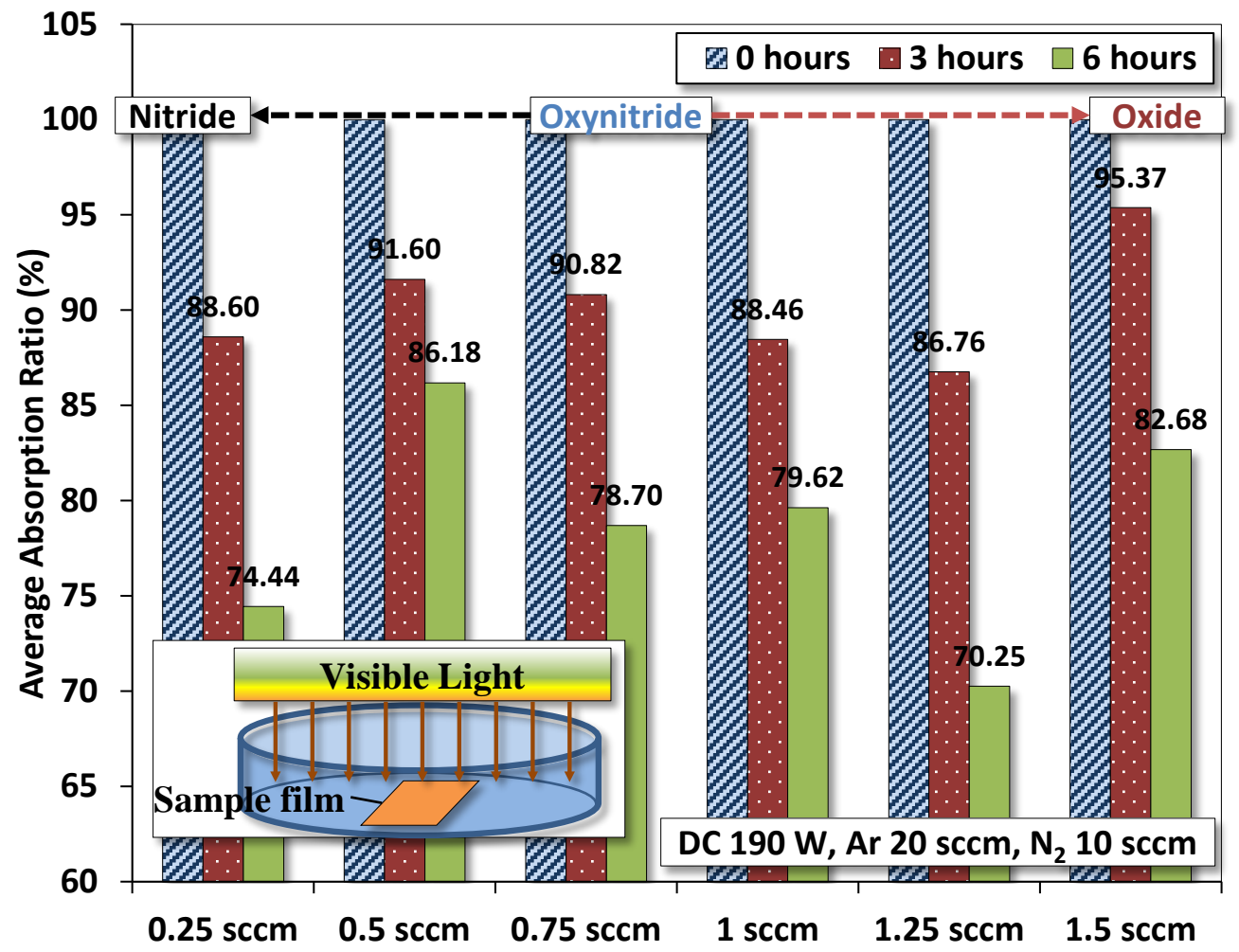

Figure 9. Photodegradation of methyl orange by various annealed oxynitride films under visible light. 


\section{Discussion}

\subsection{Optimal Choice for Photocatalysis}

The purpose of various material characterizations in this study is to provide us an optimal window of deposition parameters (oxygen flow rate) for the fabrication of tantalum oxynitride films with appropriate microstructures, enabling photocatalytic function. The following is a summary of different experimental results for obtaining a photocatalytic tantalum oxynitrides film:

- Crystalline phases: Both XRD and Raman detects the formation in films for $\mathrm{O}_{2}$ flow between $\sim 0.25$ and $\sim 1.25 \mathrm{sccm}$;

- Limited oxygen: EDS roughly indicates that the content in films can be maintained for $\mathrm{O}_{2}$ flow less than $1.5 \mathrm{sccm}$;

- Semi-conductivity: Four-point probe and Hall effect analyzer predict finite electrical resistivity for $\mathrm{O}_{2}$ flow between $\sim 0.25$ and $\sim 1.0 \mathrm{sccm}$;

- Semi-transparent with sufficient optical absorption: UV-Vis-NIR observes such for $\mathrm{O}_{2}$ flow between $\sim 0.5-\sim 1.5 \mathrm{sccm}$;

- Intra-bands: Tauc plot estimates the presence of dual optical bandgaps for $\mathrm{O}_{2}$ flow between $\sim 0.5$ and $\sim 1.5 \mathrm{sccm}$;

- Efficiency: Photodegradation of methyl orange estimates higher efficiency for films deposited by $\sim 0.25$ and $1.25 \mathrm{sccm} \mathrm{O}_{2}$ flow.

Combining results from all the above assessments, we suggest that annealed tantalum oxynitride films deposited under $\sim 0.25-1.5 \mathrm{sccm} \mathrm{O}_{2}$ supply should be capable of photocatalysis in our current setups for magnetron sputtering.

\subsection{Electrical and Optical Characters Comparison}

We briefly compare our results with few previous studies with a focus on the electrical resistivity and optical bandgaps as these two measurements are straight without further interpretations. A quantitative comparison is nearly impossible due to various factors such as deposition conditions, film microstructures, and hardware controls.

For electrical resistivity, our crystalline tantalum oxynitride samples present values of $1 \times 10^{-2}-5.9 \times 10^{1} \Omega \mathrm{cm}$. The amorphous tantalum oxynitride (Ta-O-N) films are $\sim 4 \times 10^{-1} \Omega \mathrm{cm}$ in [38]; Ta-N-O thin films by reactive co-sputtering under partial pressure ratio $\mathrm{P}_{\mathrm{O}} /\left(\mathrm{P}_{\mathrm{O}}+\mathrm{P}_{\mathrm{N}}\right)=0.22-0.79$ is between $2.88 \times 10^{-4}$ and $1.15 \times 10^{4} \Omega \mathrm{cm}$ in [42]; TaON epitaxial thin films is $1 \times 10^{-2} \Omega \mathrm{cm}$ in [43]; tantalum oxynitride thin films by r.f. reactive magnetron sputtering is $4 \times 10^{-4}-1 \times 10^{-3} \Omega \mathrm{cm}$ in [44]; TaON films deposited at $2500 \mathrm{~W}$ and annealed at $500^{\circ} \mathrm{C}$ in $\mathrm{N}_{2}$ exhibited resistivity $4.6 \times 10^{-4} \Omega \mathrm{cm}$ [45].

As for the optical bandgap, our films exhibit dual bands with the high band resides between $2.63-3.18 \mathrm{eV}$. The gap between the two bands is within $1.87-2.08 \mathrm{eV}$. The amorphous tantalum oxynitride (Ta-O-N) films in [38] have a bandgap width of $2.45 \mathrm{eV}$; TaON epitaxial thin films in [43] were found to be $2.37 \mathrm{eV}$. $\mathrm{TaO}_{\mathrm{x}} \mathrm{N}_{\mathrm{y}}$ thin films under $\mathrm{Ar}$ $70 \mathrm{sccm}, 85 \% \mathrm{~N}_{2}+15 \% \mathrm{O}_{2}$ gas mixture flow $2.5-30 \mathrm{sccm}$ (partial pressure $0.02-0.24 \mathrm{~Pa}$ ) have bandgaps $2.265-1.436 \mathrm{eV}$ and valance band at 2.61-2.19 eV [46]. In fact, most tantalum oxynitrides have bandgaps between 1.9 and $2.5 \mathrm{eV}[1,3,47]$.

Lastly, a tentative, non-quantitative comparison for the photodegradation of methylene orange between our results and a recent study in [46] can provide a clue on the efficiency of TaON films under visible light. Our results indicate that TaON by $0.5-1.5 \mathrm{sccm} \mathrm{O}_{2}$ degrades 14 to $29.5 \%$ of methylene orange, while it is reported around $10 \%$ for $\mathrm{TaON}$ under partial pressure $0.02-0.24 \mathrm{~Pa}$ of $85 \% \mathrm{~N}_{2}+15 \% \mathrm{O}_{2}$ gas mixture. Reference [46] provides abundant results from various characterizations and tests for sputtered tantalum oxynitride films.

\section{Conclusions}

Tantalum oxynitride films were deposited by sputtering under a fixed nitrogen flow $(10 \mathrm{sccm})$ but variable oxygen flow $(0-4 \mathrm{sccm})$. Post rapid thermal annealing process was conducted at $800^{\circ} \mathrm{C}$ for $5 \mathrm{~min}$ to transform the deposited film from amorphous into 
crystalline. The films were characterized by XRD and Raman for their crystal structures; SEM for surface morphologies, EDS for surface chemical compositions, Four-point probe and Hall effect analyzer for electrical resistivity, and UV-VIS-NIR spectroscopy for optical transmittance, reflectance, and absorbance. Tauc-plot and Beer-Lambert law were used to estimate the optical band gaps of films from the UV-VIS-NIR spectra. Results indicate that under low oxygen supply $(0.25-1.0 \mathrm{sccm})$, the deposited films are nitride-rich, lower electrically resistive, brown in color, and have low transparency. As the oxygen flow rate increased to 1.0-2.0 sccm, the films changed their colors from brown to yellow and light green with higher transparency and electrical resistivity. These semi-transparent films are oxynitrides with double optical bands at the energy level of visible light. When the oxygen flow rate exceeds $2.0 \mathrm{sccm}$, films turn into totally transparent oxides. These oxides have wide optical band gaps ( $>3.4 \mathrm{eV}$ ) only utilizable by the photons of UV light.

Based upon the results of XRD, Raman, EDS, electrical resistivity, and UV-VIS-NIR, we selected the annealed films deposited under $0.5-1.5 \mathrm{sccm} \mathrm{O}_{2}$ supply for the photodegradation test against methyl orange in DI water. Results from the degradation test indicate that annealed films deposited between 0.25 and $1.5 \mathrm{sccm} \mathrm{O}_{2}$ flow can degrade $14 \%$ or more methyl orange solution when continuously exposed to simulated solar light after six hours.

Author Contributions: Individual contributions for this study are specified in the following: Conceptualization, C.L. and J.-H.H.; methodology, C.L. and J.-H.H.; software, Y.R.C.; validation, C.L., J.-H.H. and Y.R.C.; formal analysis, C.L. and Y.R.C.; investigation, C.L., J.-H.H. and Y.R.C.; resources, C.L. and J.-H.H.; data curation, Y.R.C.; writing—original draft preparation, C.L.; writing-review and editing, C.L. and J.-H.H.; visualization, C.L. and Y.R.C.; supervision, C.L. and J.-H.H.; project administration, C.L.; funding acquisition, C.L. and J.-H.H. All authors have read and agreed to the published version of the manuscript.

Conflicts of Interest: The authors declare no conflict of interest.

\section{Appendix A Estimated Crystal Size}

Table A1 gives estimated crystal sizes of major peaks in XRD using Sherrer's formula. The selection is based on the intensity of peaks, and for brevity only five or six are tabulated for each oxygen flow rate.

Table A1. Estimated crystal size for major peaks in XRD.

\begin{tabular}{|c|c|c|c|}
\hline $\mathrm{O}_{2}$ Flow Rate (sccm) & 2-Theta & Est. Crystal Size (̊̊) & $(h, k, l)$ \\
\hline \multirow[t]{5}{*}{0 sccm, TaN } & 36.28 & 83.60 & $(1,2,1)$ \\
\hline & 42.08 & 88.85 & $(0,0,2)$ \\
\hline & 27.99 & 70.58 & $(2,0,0)$ \\
\hline & 22.99 & 94.82 & $(1,0,1)$ \\
\hline & 60.98 & 67.84 & $(3,1,2)$ \\
\hline \multirow[t]{5}{*}{$0.25 \mathrm{sccm}, \mathrm{TaON}$} & 31.82 & 173.18 & unknown \\
\hline & 36.76 & 147.64 & $(2,0,0)$ \\
\hline & 29.14 & 96.23 & $(-1,1,1)$ \\
\hline & 53.08 & 167.86 & $(-2,2,1)$ \\
\hline & 28.44 & 116.25 & $(1,11,0)$ \\
\hline \multirow[t]{6}{*}{$0.5 \mathrm{sccm}, \mathrm{TaON}$} & 29.19 & 151.18 & $(-1,1,1)$ \\
\hline & 32.79 & 132.71 & $(1,1,1)$ \\
\hline & 31.72 & 155.24 & unknown \\
\hline & 36.74 & 169.45 & $(2,0,0)$ \\
\hline & 52.24 & 169.50 & $(-1,2,2)$ \\
\hline & 35.26 & 87.84 & $(0,0,2)$ \\
\hline
\end{tabular}


Table A1. Cont.

\begin{tabular}{|c|c|c|c|}
\hline $\mathrm{O}_{2}$ Flow Rate (sccm) & 2-Theta & Est. Crystal Size (̊̊) & $(h, k, l)$ \\
\hline \multirow[t]{5}{*}{$0.75 \mathrm{sccm}, \mathrm{TaON}$} & 29.18 & 137.28 & $(-1,1,1)$ \\
\hline & 32.81 & 144.53 & $(1,1,1)$ \\
\hline & 36.76 & 143.84 & $(2,0,0)$ \\
\hline & 35.27 & 77.98 & $(0,0,2)$ \\
\hline & 52.20 & 171.11 & $(2,2,0)$ \\
\hline \multirow[t]{5}{*}{$1.0 \mathrm{sccm}, \mathrm{TaON}$} & 29.21 & 148.72 & $(-1,1,1)$ \\
\hline & 32.83 & 156.26 & $(1,1,1)$ \\
\hline & 36.79 & 185.22 & $(2,0,0)$ \\
\hline & 35.80 & 186.35 & $(0,2,0)$ \\
\hline & 52.24 & 205.29 & $(-1,2,2)$ \\
\hline \multirow[t]{5}{*}{$1.25 \mathrm{sccm}, \mathrm{TaON}$} & 29.01 & 90.97 & $(2,1,1)$ \\
\hline & 36.78 & 151.39 & $(2,0,0) *$ \\
\hline & 32.87 & 150.05 & $(1,1,1)$ \\
\hline & 28.56 & 126.51 & $(-1,1,1)$ * \\
\hline & 52.28 & 184.36 & $(-1,2,2)$ \\
\hline \multirow[t]{6}{*}{$1.5 \mathrm{sccm}, \mathrm{Ta}_{2} \mathrm{O}_{5}$} & 36.92 & 161.37 & $(2,0,0)$ \\
\hline & 22.94 & 166.45 & $(0,0,1)$ \\
\hline & 55.75 & 101.32 & $(1,11,2)$ \\
\hline & 50.42 & 95.13 & $(3,3,1)$ \\
\hline & 28.48 & 157.92 & $(-1,1,1)$ \\
\hline & 46.74 & 189.37 & $(3,7,0)$ \\
\hline \multirow[t]{6}{*}{$2.0 \mathrm{sccm}, \mathrm{Ta}_{2} \mathrm{O}_{5}$} & 28.59 & 181.37 & $(-1,1,1)$ \\
\hline & 36.98 & 181.71 & $(2,0,0)$ \\
\hline & 22.99 & 199.19 & $(0,0,1)$ \\
\hline & 55.84 & 99.90 & $(1,11,2)$ \\
\hline & 50.60 & 90.96 & $(3,3,1)$ \\
\hline & 46.86 & 202.29 & $(3,7,0)$ \\
\hline \multirow[t]{6}{*}{$4.0 \mathrm{sccm}, \mathrm{Ta}_{2} \mathrm{O}_{5}$} & 23.01 & 227.09 & $(0,0,1)$ \\
\hline & 28.65 & 192.92 & $(-1,1,1)$ \\
\hline & 37.03 & 214.82 & $(2,0,0)$ \\
\hline & 55.83 & 121.33 & $(1,11,2)$ \\
\hline & 46.91 & 240.55 & $(3,7,0)$ \\
\hline & 50.68 & 115.81 & $(3,3,1)$ \\
\hline
\end{tabular}

* Peaks should belong to $\mathrm{Ta}_{2} \mathrm{O}_{5}$.

\section{Appendix B SEM}

The surface morphology of selected annealed films by SEM is shown in Figure A1. Three sample films deposited under $\mathrm{O}_{2}$ flow rates of $0.5,1.0$, and $1.5 \mathrm{sccm}$ were chosen to demonstrate the transition from the phase of nitride-rich to oxide-rich. Among the three samples, the surface of films deposited under $1.0 \mathrm{sccm}$ oxygen supply appears to be the smoothest one. This could indicate that the condition of $1.0 \mathrm{sccm}$ oxygen supply provides an optimal balance between the nitride and the oxide to result in more coherent microstructures. It is also noticed that there are many spherical precipitates at 0.5 and $1.5 \mathrm{sccm} \mathrm{O}_{2}$ flow that could be Ta metallic phases, but their dimensions are too small to be distinguished by our EDS system. 

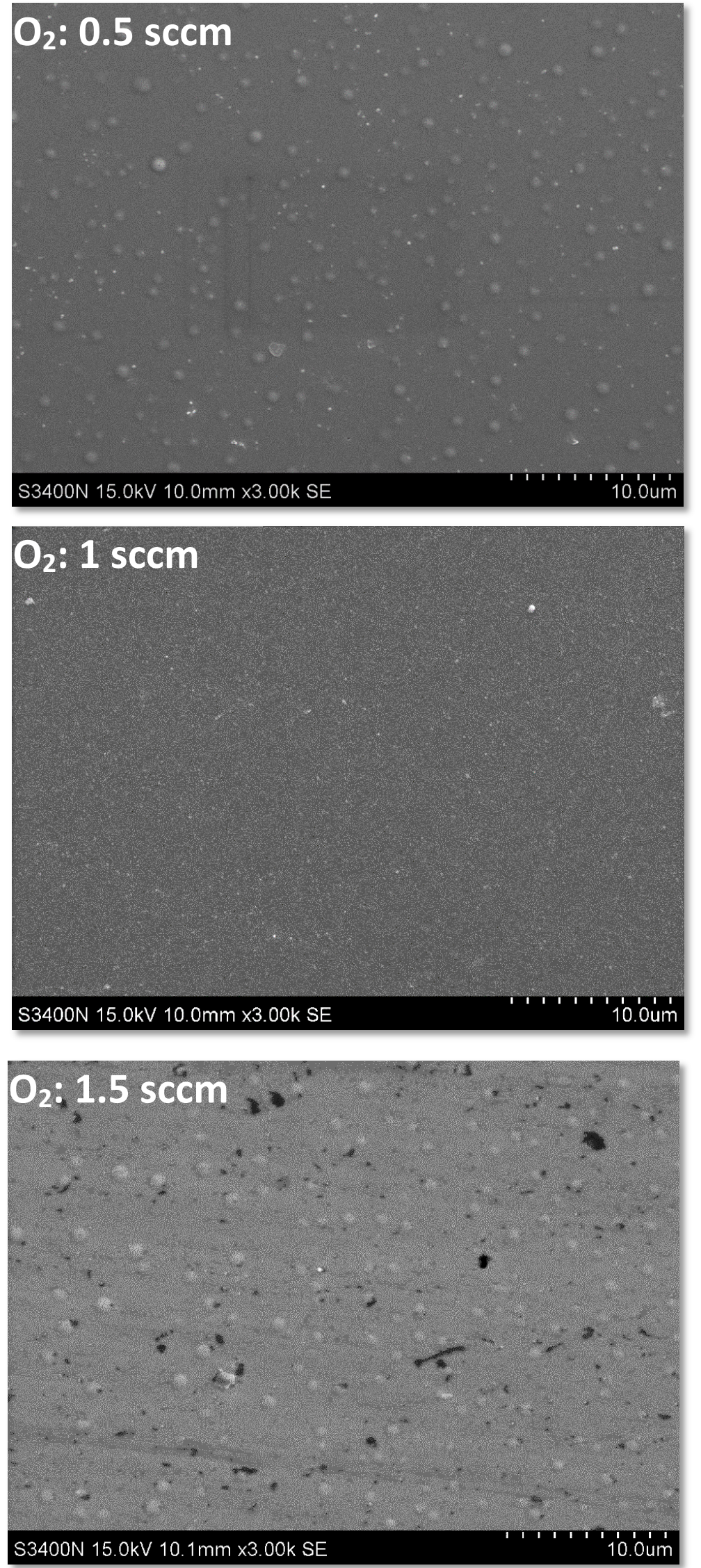

Figure A1. Selected SEM images of annealed films under different oxygen flow rates. 


\section{References}

1. Ahmed, M.; Guo, X. A review of metal oxynitrides for photocatalysis. Inorg. Chem. Front. 2016, 3, 578-590. [CrossRef]

2. Cubillos, G.I.; Bethencourt, M.; Olaya, J.J. Corrosion resistance of zirconium oxynitride coatings deposited via DC unbal-anced magnetron sputtering and spray pyrolysis-nitriding. Appl. Surf. Sci. 2015, 327, 288-295. [CrossRef]

3. Maeda, K.; Kazunari, D. Oxynitride materials for solar water splitting. MRS Bull. 2011, 36, 25-31. [CrossRef]

4. Cao, G.Z.; Metselaar, R. $\alpha^{\prime}$-Sialon Ceramics: A Review. Chem. Mater. 1991, 3, 242-252. [CrossRef]

5. Luo, Z.; Qu, G.; Zhang, Y.; Cui, L.; Lu, A. Transparent oxynitride glasses: Synthesis, microstructure, optical transmittance and ballistic resistance. J. Non-Cryst. Solids 2013, 378, 45-49. [CrossRef]

6. Lei, P.; Guo, S.; Zhu, J.; Dai, B.; Liu, G.; Wang, Y.; Han, J. Enhanced mechanical properties of HfO2film by nitrogen doping. Surf. Eng. 2016, 32, 585-588. [CrossRef]

7. Gibson, J.S.K.-L.; Rezaei, S.; Rueß, H.; Hans, M.; Music, D.; Wulfinghoff, S.; Schneider, J.M.; Reese, S.; Korte-Kerzel, S. From quantum to continuum mechanics: Studying the fracture toughness of transition metal nitrides and oxynitrides. Mater. Res. Lett. 2018, 6, 142-151. [CrossRef]

8. Ebbinghaus, S.G.; Abicht, H.-P.; Dronskowski, R.; Müller, T.; Reller, A.; Weidenkaff, A. Perovskite-related oxynitrides—Recent developments in synthesis, characterization and investigations of physical properties. Prog. Solid State Chem. 2009, 37, 173-205. [CrossRef]

9. Iqbal, N.; Khan, I.; Yamani, Z.H.; Qurashi, A. Sonochemical Assisted Solvothermal Synthesis of Gallium Oxynitride Nanosheets and their Solar-Driven Photoelectrochemical Water-Splitting Applications. Sci. Rep. 2016, 6, 32319. [CrossRef]

10. Shaheen, B.S.; Hafez, A.M.; Murali, B.; Kirmani, A.R.; Amassian, A.; Mohammed, O.F.; Allam, N.K. 10-fold enhancement in light-driven water splitting using niobium oxynitride microcone array films. Sol. Energy Mater. Sol. Cells 2016, 151, 149-153. [CrossRef]

11. Black, A.P.; Suzuki, H.; Higashi, M.; Frontera, C.; Ritter, C.; De, C.; Sundaresan, A.; Abe, R.; Fuertes, A. New rare earth hafnium oxynitride perovskites with photocatalytic activity in water oxidation and reduction. Chem. Commun. 2018, 54, 1525-1528. [CrossRef]

12. Yang, M.-C.; Yang, T.-S.; Wong, M.-S. Nitrogen-doped titanium oxide films as visible light photocatalyst by vapor deposition. Thin Solid Films 2004, 469, 1-5. [CrossRef]

13. Kitano, M.; Matsuoka, M.; Ueshima, M.; Anpo, M. Recent developments in titanium oxide-based photocatalysts. Appl. Catal. A Gen. 2007, 325, 1-14. [CrossRef]

14. Lai, K.; Huang, J.Y.; Zhang, H.F.; Subramaniam, V.P.; Tang, Y.X.; Gong, D.G.; Sundar, L.; Sun, L.; Chen, Z.; Lin, C.J. Nitrogen-doped $\mathrm{TiO} 2$ nanotube array films with enhanced photocatalytic activity under various light sources. J. Hazard Mater. 2010, 184, 855-863. [CrossRef]

15. Triantis, T.M.; Fotiou, T.; Kaloudis, T.; Kontos, A.G.; Falaras, P.; Dionysiou, D.D.; Pelaez, M.; Hiskia, A. Photocatalytic deg-radation and mineralization of microcystin-LR under UV-A, solar and visible light using nanostructured nitrogen doped $\mathrm{TiO}_{2}$. J. Hazard Mater. 2012, 211, 196-202. [CrossRef]

16. Fuertes, A. Synthetic approaches in oxynitride chemistry. Prog. Solid State Chem. 2018, 51, 63-70. [CrossRef]

17. Watanabe, T.; Tajima, K.; Li, J.; Matsushita, N.; Yoshimura, M. Low-temperature Ammonothermal Synthesis of LaTaON 2 . Chem. Lett. 2011, 40, 1101-1102. [CrossRef]

18. Higashi, M.; Domen, K.; Abe, R. Fabrication of an Efficient $\mathrm{BaTaO}_{2} \mathrm{~N}$ Photoanode Harvesting a Wide Range of Visible Light for Water Splitting. J. Am. Chem. Soc. 2013, 135, 10238-10241. [CrossRef] [PubMed]

19. Kim, Y.-I.; Si, W.; Woodward, P.M.; Sutter, E.; Park, S.; Vogt, T. Epitaxial Thin-Film Deposition and Dielectric Properties of the Perovskite Oxynitride $\mathrm{BaTaO}_{2}$ N. Chem. Mater. 2007, 19, 618-623. [CrossRef]

20. Khodaei, M.; Yaghobizadeh, O.; Alhosseini, S.H.N.; Esmaeeli, S.; Mousavi, S.R. The effect of oxide, carbide, nitride and boride additives on properties of pressureless sintered SiC: A review. J. Eur. Ceram. Soc. 2019, 39, 2215-2231. [CrossRef]

21. Chen, H.-Y.; Lu, F.-H. Oxidation behavior of titanium nitride films. J. Vac. Sci. Technol. A 2005, 23, 1006-1009. [CrossRef]

22. Wright, J.S.; Lim, W.; Norton, D.P.; Pearton, S.J.; Ren, F.; Johnson, J.L.; Ural, A. Nitride and oxide semiconductor nanostruc-tured hydrogen gas sensors. Semicond. Sci. Technol. 2010, 25, 024002. [CrossRef]

23. Ghosh, S.; Jeong, S.M.; Polaki, S.R. A review on metal nitrides/oxynitrides as an emerging supercapacitor electrode beyond oxide. Korean J. Chem. Eng. 2018, 35, 1389-1408. [CrossRef]

24. Bahari, A.; Morgen, P.; Pedersen, K.; Li, Z.S. Growth of a stacked silicon nitride/silicon oxide dielectric on Si (100). J. Vac. Sci. Technol. B Microelectron. Nanometer Struct. 2006, 24, 2119. [CrossRef]

25. Leitao, A.B.V.; Lima, C.L.; Viana, B.C.; Neto, B.; Costa, J.A.P.; Costa, T.H.C.; De Souza, I.A.; Naeem, M.; Sousa, R.R.M. Novel synthesis of molybdenum nitride/oxide on AISI-316 steel assisted with active screen plasma treatment. Mater. Res. Express 2019, 6, 116501. [CrossRef]

26. Dietl, T. A ten-year perspective on dilute magnetic semiconductors and oxides. Nat. Mater. 2010, 9, 965-974. [CrossRef]

27. Gerstenberg, D.; Calbick, C.J. Effects of nitrogen, methane, and oxygen on structure and electrical properties of thin tantalum films. J. Appl. Phys. 1964, 35, 402-407. [CrossRef]

28. Cardonne, S.; Kumar, P.; Michaluk, C.; Schwartz, H. Tantalum and its alloys. Int. J. Refract. Met. Hard Mater. 1995, 13, $187-194$. [CrossRef] 
29. Tauc, J.; Grigorovici, R.; Vancu, A. Optical Properties and Electronic Structure of Amorphous Germanium. Phys. Status Solidi B 1966, 15, 627-637. [CrossRef]

30. Tauc, J. Optical properties and electronic structure of amorphous Ge and Si. Mater. Res. Bull. 1968, 3, 37-46. [CrossRef]

31. Beer, A. Bestimmung der absorption des rothen lichts in farbigen flussigkeiten. Ann. Phys. 1852, 162, 78-88. [CrossRef]

32. Rahman, M.; Krishna, K.; Soga, T.; Jimbo, T.; Umeno, M. Optical properties and X-ray photoelectron spectroscopic study of pure and Pb-doped TiO2 thin films. J. Phys. Chem. Solids 1999, 60, 201-210. [CrossRef]

33. Tang, H.; Prasad, K.; Sanjinès, R.; Schmid, P.E.; Lévy, F. Electrical and optical properties of TiO2anatase thin films. J. Appl. Phys. 1994, 75, 2042-2047. [CrossRef]

34. Sharma, P.; Vashistha, M.; Jain, I.P. Optical properties of Ge20Se80-xBix thin films. J. Optoelectron. Adv. Mater. 2005, 7, 2647-2654.

35. Li, C.; Hsieh, J.H.; Hung, M.T.; Huang, B.Q. The deposition and microstructure of amorphous tungsten oxide films by sputtering. Vacuum 2015, 118, 125-132. [CrossRef]

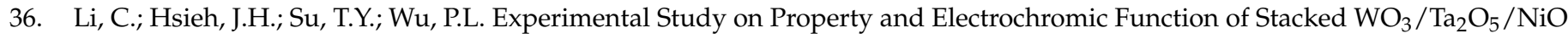
Films by Sputtering. Thin Solid Films 2018, 66, 373-379. [CrossRef]

37. Salamon, K.; Mičetić, M.; Sancho-Parramon, J.; Radović, I.B.; Siketić, Z.; Šarić, I.; Petravić, M.; Bernstorff, S. $\beta$-TaON thin films: Production by reactive magnetron sputtering and the question of non-stoichiometry. J. Phys. D Appl. Phys. 2019, $52,305304$. [CrossRef]

38. Čapek, J.; Batková, Š.; Haviar, S.; Houška, J.; Čerstvý, R.; Zeman, P. Effect of annealing on structure and properties of Ta-O-N films prepared by high power impulse magnetron sputtering. Ceram. Int. 2019, 45, 9454-9461. [CrossRef]

39. Nurlaela, E.; Harb, M.; Del Gobbo, S.; Vashishta, M.; Takanabe, K. Combined experimental and theoretical assessments of the lattice dynamics and optoelectronics of $\mathrm{TaON}$ and $\mathrm{Ta}_{3} \mathrm{~N}_{5}$. J. Solid State Chem. 2015, 229, 219-227. [CrossRef]

40. Li, P.; Fan, W.; Li, Y.; Sun, H.; Cheng, X.; Zhao, X.; Jiang, M. First-Principles Study of the Electronic, Optical Properties and Lattice Dynamics of Tantalum Oxynitride. Inorg. Chem. 2010, 49, 6917-6924. [CrossRef] [PubMed]

41. Ivanda, M.; Clasen, R.; Hornfeck, M.; Kiefer, W. Raman spectroscopy on SiO2 glasses sintered from nanosized particles. J. Non-Cryst. Solids 2003, 322, 46-52. [CrossRef]

42. Chung, C.; Chen, T.; Chang, N. Effect of reactive gases flow ratios on the microstructure and electrical resistivity of Ta-N-O thin films by reactive co-sputtering. Thin Solid Films 2011, 519, 5099-5102. [CrossRef]

43. Suzuki, A.; Hirose, Y.; Oka, D.; Nakao, S.; Fukumura, T.; Ishii, S.; Sasa, K.; Matsuzaki, H.; Hasegawa, T. High-Mobility Electron Conduction in Oxynitride: Anatase TaON. Chem. Mater. 2014, 26, 976-981. [CrossRef]

44. Ayerdi, I.; Castaño, E.; García-Alonso, A.; Gracia, F.J. Characterization of tantalum oxynitride thin films as high-temperature strain gauges. Sens. Actuator A Phys. 1995, 46, 218-221. [CrossRef]

45. Lee, P.-Y.; Lin, C.-X.; Lee, Y.-C. Microstructure and electrical property of tantalum oxynitride thin films prepared using high-power impulse reactive magnetron sputtering. Jpn. J. Appl. Phys. 2020, 59, 116502. [CrossRef]

46. Cristea, D.; Cunha, L.; Gabor, C.; Ghiuta, I.; Croitoru, C.; Marin, A.; Velicu, L.; Besleaga, A.; Vasile, B. Tantalum Oxynitride Thin Films: Assessment of the Photocatalytic Efficiency and Antimicrobial Capacity. Nanomater 2019, 9, 476. [CrossRef]

47. Zhen, C.; Chen, R.; Wang, L.; Liu, G.; Cheng, H.-M. Tantalum (oxy)nitride based photoanodes for solar driven water oxidation. J. Mater. Chem. A 2016, 4, 2783-2800. [CrossRef] 